\title{
The addition of hydromorphone to epidural fentanyl does not affect analgesia in early labour
}

\author{
[L'addition d'hydromorphone à l'injection épidurale de fentanyl n'affecte pas \\ l'analgésie au début du travail]
}

\begin{abstract}
Robert K. Parker DO, Neil Roy Connelly MD, Tanya Lucas MD, Uzma Faheem MD, Asad Syed Rizvi MD, Mervat El-Mansouri MD, Nikhil Thakkar MD, Ramchander Kamasumadram MD, Kelly Dixon RN, Steven M. Dunn MD, Charles Gibson RN MA
\end{abstract}

Purpose: Epidural fentanyl after a lidocaine and epinephrine test dose, provides adequate analgesia and allows for ambulation during early labour. The current study was designed to determine the influence of hydromorphone added to an epidural fentanyl bolus (e.g., whether there is an increase in duration of analgesia).

Methods: Forty-four labouring primigravid women, at less than 5 $\mathrm{cm}$ cervical dilation, who requested epidural analgesia were enrolled in this randomized, double-blind study. After a $3 \mathrm{~mL}$ test dose of lidocaine with epinephrine, patients received fentanyl 100 $\mu \mathrm{g}$ (in $10 \mathrm{~mL}$ volume). They randomly received the fentanyl with either saline or hydromorphone $(300 \mu \mathrm{g})$.

After administration of the initial analgesic, pain scores and side effects were recorded for each patient at ten, 20, and $30 \mathrm{~min}$, and every 30 min thereafter, by an observer blinded to the technique used.

Results: The patients were taller in the hydromorphone group $(P$ $<0.04)$. There were no other demographic differences between the two groups. The mean duration prior to re-dose was not significantly different in the group that received hydromorphone (135 $\pm 52 \mathrm{~min}$ ) compared to the control group (145 $\pm 46 \mathrm{~min}$ ). Side effects were similar between the two groups. No patient in either group experienced any detectable motor block.

Conclusion: In early labouring patients, the addition of hydromorphone $(300 \mu \mathrm{g})$ to epidural fentanyl ( $100 \mu \mathrm{g}$ after a lidocaine and epinephrine test dose) neither prolongs the duration of analgesia nor affects the ability to ambulate, and cannot be recommended according to the current study.

Objectif: L'administration épidurale de fentanyl suivant une dose test de lidocaïne et d'épinéphrine fournit une analgésie adéquate et permet de marcher au début du travail obstétrical. La présente étude cherchait à déterminer l'influence d'un ajout d'hydromorphone au bolus de fentanyl épidural. Entre autres, l'analgésie est-elle prolongée?

Méthode : Quarante-quatre primigestes en travail chez qui la dilatation du col était de moins de $5 \mathrm{~cm}$ et qui avaient demandé une analgésie épidurale ont été recrutées pour l'étude randomisée et à double insu. Après avoir reçu une dose test de $3 \mathrm{~mL}$ de lidocaïne avec de l'épinéphrine, les patientes ont eu $100 \mu \mathrm{g}$ de fentanyl (dans un volume $10 \mathrm{~mL}$ ). Elles ont reçu de façon aléatoire le fentanyl et, soit une solution salée, soit de l'hydromorphone (300 $\mu \mathrm{g})$. Après l'administration de l'analgésique initial, les scores de douleur et les effets secondaires ont été enregistrés pour chaque patiente à dix, 20 et 30 min et à toutes les 30 min par la suite par un observateur objectif.

Résultats : La seule caractéristique personnelle différente entre les patientes des deux groupes était que les patientes ayant reçu l'hydromorphone étaient plus grandes $(P<0,04)$. Que ce soit avec l'hydromorphone (1 $35 \pm 52 \mathrm{~min}$ ) ou la substance témoin ( $45 \pm 46$ min), le temps moyen précédant une seconde dose était comparable. Les effets secondaires ont été similaires dans les deux groupes. Aucune patiente n'a expérimenté de blocage moteur détectable.

Conclusion : Au début du travail, l'ajout d'hydromorphone (300 Mg) à l'administration péridurale de fentanyl ( $100 \mu \mathrm{g}$ après une dose test de lidocaïne et d'épinéphrine) ne prolonge pas l'analgésie et n'affecte pas la capacité de marcher. II ne peut être recommandé selon la présente étude.

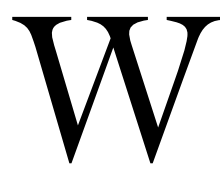

E previously showed that epidural fentanyl or sufentanil, after a lidocaine-epinephrine test dose, provides approximately two hours of analgesia, while allowing patients to ambulate. ${ }^{1-6}$ Fentanyl is the most commonly chosen opioid at our institution for early labour ambulatory epidurals based on its low

From the Department of Anesthesiology, Baystate Medical Center, Springfield, Massachusetts, USA.

Address correspondence to: Dr. Neil Roy Connelly, Department of Anesthesiology, Baystate Medical Center, 759 Chestnut Street,

Springfield, Massachusetts 01199, USA. Phone: 413-794-4325; Fax: 413-794-5349; E-mail: neil.roy.connelly@bhs.org Accepted for publication January 8, 2002.

Revision accepted March 18, 2002. 
cost and the fact there was a lack of significant analgesic difference compared to sufentanil. ${ }^{3}$

In a pilot study, hydromorphone $300 \mu \mathrm{g}$ following a lidocaine-epinephrine test dose demonstrated an analgesic onset time of greater than $20 \mathrm{~min}$, which was determined to be too long to be clinically useful. We postulated that combining a "quick-onset" short-acting opioid (i.e., fentanyl) with a longer-onset, longeracting opioid (i.e., hydromorphone) would achieve the benefits of both medications: a quick-onset, long duration "ambulatory" epidural. We thus undertook this study to determine the influence of hydromorphone on the duration of analgesia when administered along with fentanyl after a lidocaine and epinephrine test dose, in primigravid patients during the early first stage of labour.

\section{Methods}

Before this study was initiated, Institutional Review Board approval was obtained. Forty-four primigravid ASA physical status I or II obstetric patients, at greater than 36 weeks of gestation, who had requested labour analgesia, gave written informed consent. Patients were excluded if cervical dilation was greater than $5 \mathrm{~cm}$, if they had received $i v$ opioid agonists or agonist/antagonists, had pre-eclampsia, or had a contraindication to fentanyl or hydromorphone. A normal fetal heart rate pattern (absence of decelerations) was required for inclusion in the study. Patients were randomized to group C (control) or group HYD (hydromorphone) using a random series of 44 numbers generated with Microsoft Excel's Randbetween function.

Before the procedure began, the patients' vital signs (blood pressure, heart rate, and respiratory rate) were documented, and the patients were asked to relate any symptoms of pruritus, nausea, or vomiting. Each patient also completed a baseline assessment using a $100-\mathrm{mm}$ visual analogue scale (VAS) for pain, with 0 representing no pain and 100 being the worst possible pain. Each patient received a minimum of $500 \mathrm{~mL}$ of Ringer's lactate solution intravenously. All procedures were performed with patients in the sitting position. A lumbar epidural catheter was inserted approximately $5 \mathrm{~cm}$ into the epidural space by using a Tuohy-Schiff needle (B-Braun Medical, Bethlehem, PA, USA). The patients then received a test dose of 3 $\mathrm{mL}$ of $1.5 \%$ lidocaine with $1: 200,000$ epinephrine. If the test dose was negative for intravascular injection (heart rate within 15 beats. $\mathrm{min}^{-1}$ of baseline values in two minutes of monitoring) and intrathecal injection (no spinal block after three minutes of monitoring), the patient was given one of two epidural injections in a double-blinded fashion as follows: group C: fentanyl
$100 \mu \mathrm{g}$ with normal saline to a total volume of $10 \mathrm{~mL}$; group HYD: fentanyl $100 \mu \mathrm{g}$ and hydromorphone $300 \mu \mathrm{g}$ with normal saline to a total volume of $10 \mathrm{~mL}$.

Patients were placed in the recumbent position with left uterine displacement. VAS scores and the severity of side effects were recorded ten, 20 , and 30 min after the administration of the study infusion and every $30 \mathrm{~min}$ thereafter. Observations were performed by an individual blinded to the analgesic technique. At the time of each assessment, vital signs, modified Bromage motor scale scores, ${ }^{7}$ pruritus, nausea, vomiting and sedation were evaluated. Motor block was defined as none, partial (just able to move the knees), almost complete (able to move the feet only), or complete (unable to move the lower extremities). Pruritus was rated as none, minimal (present with minimal symptoms), moderate (bothersome but not requiring therapy), or severe (requiring therapy). Sedation was categorized as none (awake), mild (drowsy), moderate (sleepy) or severe (unarousable). The fetal heart rate pattern was evaluated at each interval and any changes were documented. After the first $30 \mathrm{~min}$, patients were allowed to ambulate with assistance provided there was no detectable motor block and the fetal heart rate pattern was reassuring. Oxygen saturation was monitored while patients were at bedrest. The time at which each patient requested additional analgesia was recorded, vital signs were documented, pain and side effect assessments were performed, and the study period was concluded. The epidural anesthetics were subsequently managed by the anesthesia team, as appropriate, for the remainder of labour. The length of labour, incidence of Cesarean delivery, incidence of postdural puncture headache $(\mathrm{PDPH})$, and neonatal Apgar scores were recorded.

A plan for treating inadequate analgesia was standardized. If a patient did not experience adequate analgesia $20 \mathrm{~min}$ after the initial study dose, $15 \mathrm{~mL}$ of $0.125 \%$ bupivacaine would be administered via the epidural catheter. If this did not provide relief after an additional $20 \mathrm{~min}, 10 \mathrm{~mL}$ of $2 \%$ lidocaine would be administered. If this did not result in an adequate level of analgesia, then the epidural catheter would be replaced.

Before this study was instituted, a power analysis was performed assuming: a duration of fentanyl analgesia of $124 \pm 42 \mathrm{~min}, 1,3$ a hydromorphone analgesia duration of $165 \pm 45 \mathrm{~min} ; 90 \%$ power, and an alpha of 0.05 . This yielded a required sample size of 21 patients per group.

Demographic data were analyzed by using analysis of variance. Pain scores were analyzed by using the Mann- Whitney U test. Presence or absence of side effects was analyzed by contingency testing. A Kaplan- 
TABLE

\begin{tabular}{|c|c|c|c|c|c|c|c|c|}
\hline Group & $\begin{array}{l}\text { Age } \\
(y r)\end{array}$ & $\begin{array}{l}\text { Height } \\
(\mathrm{cm})\end{array}$ & $\begin{array}{l}\text { Weight } \\
(\mathrm{kg})\end{array}$ & $\begin{array}{l}\text { Gestational } \\
\text { age (weeks) }\end{array}$ & $\begin{array}{l}\text { Cesarean } \\
\text { section }(n)\end{array}$ & $\begin{array}{l}\text { Forceps/ } \\
\operatorname{vacuum}(n)\end{array}$ & $\begin{array}{l}\text { Cervical } \\
\text { dilation } \\
\text { at initial } \\
\text { dose }\end{array}$ & $\begin{array}{l}\text { Cervical } \\
\text { dilation } \\
\text { at re-dose }\end{array}$ \\
\hline $\begin{array}{l}\text { Hydromorphone/ } \\
\text { fentanyl }\end{array}$ & $27 \pm 6$ & $167 \pm 7$ & $84 \pm 16$ & $40 \pm 1$ & $9 / 21$ & $0 / 21$ & $2.9 \pm 1.2$ & $5.1 \pm 2.4$ \\
\hline Fentanyl & $26 \pm 7$ & $162 \pm 8$ & $86 \pm 18$ & $40 \pm 2$ & $6 / 21$ & $1 / 21$ & $3.1 \pm 1.1$ & $4.6 \pm 2.0$ \\
\hline
\end{tabular}

Data are expressed as mean $\pm \mathrm{SD}$. The patients in the hydromorphone group were significantly taller $(P<0.04)$ than the patients in the control group. There were no other statistically significant differences between the groups.

Meier plot of the patients remaining comfortable over time was generated. Data are expressed as mean $\pm \mathrm{SD}$. Significance was determined at the $P<0.05$ level.

\section{Results}

Forty-four patients were enrolled in the study. All patients, except one, achieved adequate initial analgesia with the epidural fentanyl; this patient did not get comfortable following the administration of epidural local anesthetic, but analgesia was achieved following replacement of the epidural catheter. One patient's data were excluded due to a protocol violation: a bupivacaine infusion was initiated immediately after the epidural medication was administered. These patients' data were excluded from analysis. The patients in the HYD group were significantly taller than those in group $\mathrm{C}(P<0.04)$. There were no other differences in demographic variables, cervical dilation at the time of enrollment, rupture of membranes, or oxytocin use between the two study groups (Table). Baseline VAS pain scores and the incidence of nausea and pruritus were similar in the two groups. The median VAS scores in both groups were decreased $81 \%$ and $69 \%$ by the 10 -min evaluation in the $\mathrm{C}$ and HYD groups, respectively $(P=$ not significant). At $20 \mathrm{~min}$, VAS scores were reduced by $88 \%$ (C) and $83 \%$ (HYD; $P=$ not significant). There was no significant difference in pain scores between the groups at any of the time points (Figure 1). The duration until re-dose was not significantly different between the $\mathrm{C}(145 \pm 46 \mathrm{~min})$ and the HYD groups $(135 \pm 52 \mathrm{~min}$; Figure 2).

Before administration of the study analgesic, 12 patients had experienced nausea (six in C, six in HYD) and five patients had vomited (three in $\mathrm{C}$, two in HYD). During the entire study period, nine patients experienced nausea (two in C, seven in HYD) and two patients vomited (two in C, zero in HYD). Four patients experienced mild sedation at least once during the study period (two in group $\mathrm{C}$, two in group HYD). No patient experienced moderate or severe

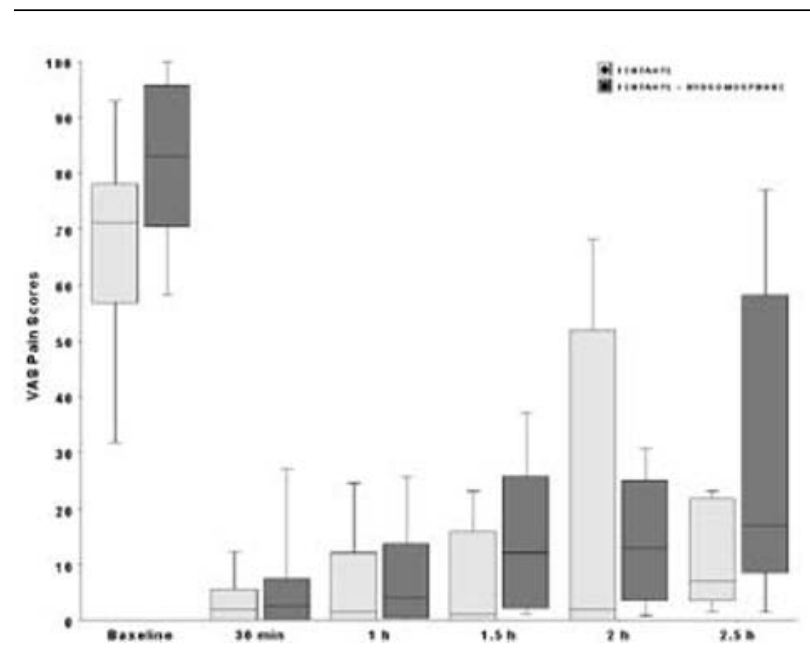

FIGURE 1 The visual analogue scale (VAS) pain scores for the two groups at time intervals up to 2.5 hours. The box represents the $25^{\text {th }}-75^{\text {th }}$ percentiles and the median is represented by the solid line. The extended bars represent the $10^{\text {th }}-90^{\text {th }}$ percentiles. Pain scores were not obtained following administration of additional analgesic medication. There were no significant differences between the groups at any time period.

sedation. At no time, did any patient experience severe pruritus. No patient required specific treatment for nausea, vomiting, or pruritus. There were three patients who reported at one time interval the presence of moderate pruritus (one in C, two in HYD).

Two patients delivered without the need for a redose (both in $\mathrm{C}$ group; $P=$ not significant). The incidence of Cesarean delivery was not significantly different between the groups (six in C; nine in HYD); none of the patients required a Cesarean delivery before the need for a re-dose. One patient had an accidental dural puncture; no patient, in either group, developed symptoms of a PDPH.

During the study period, motor block, as reflected by the Bromage score, was absent (score of 0 ) in all patients. Seventeen patients (39\%) ambulated at least 


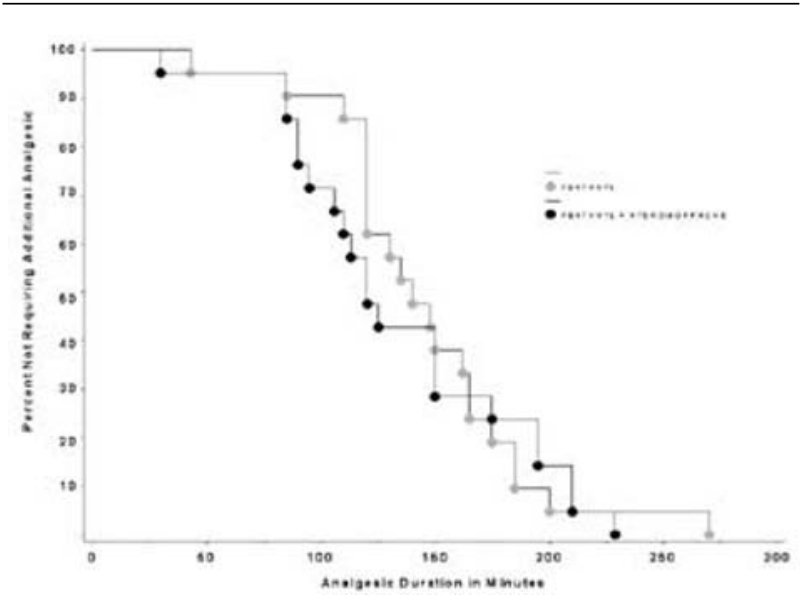

FIGURE 2 Kaplan-Meier plot of the percent of patients in each group who continued to remain comfortable.

once during their labour (ten in C, seven in HYD). Apgar scores at birth were comparable between groups.

\section{Discussion}

Epidural analgesia allowing ambulation during labour is increasingly popular, in part because of the perceived importance of preservation of motor power. We have successfully utilized epidural opioids following a lidocaine-epinephrine test dose to provide satisfactory analgesia without a significant motor block. ${ }^{1-6}$

The current study compared $100 \mu \mathrm{g}$ of fentanyl after a lidocaine and epinephrine test dose in primigravid patients with and without concomitant hydromorphone $(300 \mu \mathrm{g})$. The goal of the hydromorphone was to prolong the duration of analgesia. We did not find any prolongation of analgesia by the addition of hydromorphone. While the average height was $5 \mathrm{~cm}$ taller in the HYD group, it is unlikely that this affected the findings of this study. We chose the dose of hydromorphone for this study by extrapolation from postCesarean delivery data in which patients used an average of 300-400 $\mu \mathrm{g}$ of epidural hydromorphone per four-hour period when utilizing patient-controlled epidural analgesia. ${ }^{8,9}$ Use of a higher dose (e.g., > 500 $\mu \mathrm{g})$ may have improved the analgesia. However, use of large epidural hydromorphone doses $(900 \mu \mathrm{g})$ has been associated with significant side effects including nausea, vomiting, pruritus, and urinary retention, without causing an improvement in analgesia when compared to a lower dose $(300 \mu \mathrm{g})^{8}$. An additional study in postCesarean patients demonstrated similar side effects and efficacy with hydromorphone $600 \mu \mathrm{g}$ vs morphine $3 \mathrm{mg}$. One-third of patients in the HYD $600 \mu \mathrm{g}$ group received $i v$ diphenhydramine to treat pruritus. ${ }^{10}$ With this current study we were reluctant to increase the hydromorphone dose above $300 \mu \mathrm{g}$ risking the increase in side effects.

In treating patients with ambulatory epidural injections, we prefer the epidural opioid technique, rather than the combined spinal epidural (CSE) technique, because the former avoids an added step, the expense of a CSE needle, and the necessity of an intentional dural puncture. ${ }^{1-6}$ The accidental dural puncture rate using the epidural technique has been reported to be $0.69-4.2 \%{ }^{11,12}$ We had one accidental dural puncture in our study of 44 patients (with epidural catheters placed by residents in a teaching institution).

When epidural fentanyl $(50 \mu \mathrm{g})$ is combined with clonidine $(120 \mu \mathrm{g})$ the mean duration of analgesia was 80 min. ${ }^{13}$ In a study comparing CSE with epidural fentanyl ( $100 \mu \mathrm{g}$ in $10 \mathrm{~mL}$ volume) the mean duration of analgesia with epidural fentanyl was 83 min. ${ }^{14}$ In a study utilizing $40 \mu \mathrm{g}$ epidural fentanyl with $20 \mathrm{~mL}$ $0.08 \%$ bupivacaine, the analgesic duration was shown to be $91 \pm 24 \mathrm{~min}^{15}$ These times are significantly less than the analgesia in our previous studies of epidural opioids, ${ }^{1-4}$ as well as in the current study (135-145 min). However, Breen et al.'s study population included both primigravidous and multigravidous patients. ${ }^{14}$ Any study only evaluating primigravidous patients in early labour (and excluding multigravidous patients) probably results in patient groups with longer labour and is the probable reason for the longer and more consistent duration of analgesia in our studies. The analgesic duration in both groups in the current study is consistent with that of epidural fentanyl or sufentanil when utilized for labour pain management. ${ }^{1-4}$ Whether the hydromorphone resulted in no effect due to a change in the intensity of pain as labour progressed (such that opioid alone is inadequate), or that the analgesic duration of hydromorphone in labour is not significantly different than that of fentanyl, remains unclear. A study of postCesarean delivery pain found no difference between epidural morphine $3 \mathrm{mg}$ and hydromorphone $600 \mu \mathrm{gg} .{ }^{10}$ While postCesarean delivery pain and labour pain cannot be equated, these results leave a question unanswered. Namely, whether $300 \mu \mathrm{g}$ hydromorphone is adequate to demonstrate the prolonged duration we had hypothesized. Further studies should include a doseresponse analysis.

Use of a lidocaine and epinephrine test dose has been implicated in a decreased ability for parturients to ambulate. ${ }^{16}$ However, all patients in Cohen's study 
received an initial $12 \mathrm{~mL}$ epidural bolus of bupivacaine $(0.0625 \%$ or $0.125 \%)$ in addition to the lidocaine-epinephrine test dose. Epidural $0.1 \%$ bupivacaine with sufentanil, as part of a patient-controlled epidural analgesia technique, results in detectable motor block in approximately $20 \%$ of patients. ${ }^{17}$ Our use of epidural opioid after a test dose, without the use of adjuvant local anesthetic, does not result in significant motor block. ${ }^{1-6}$ We believe that when sufficient opioid is utilized initially, an initial bolus of local anesthesia is avoided, and ambulation can be achieved without eliminating the test dose. Although the usefulness of the test dose has been challenged recently, ${ }^{16}$ we believe that it does improve the ability to detect intravascular and intrathecal catheter placement.

We have demonstrated satisfactory results with epidural fentanyl after a lidocaine and epinephrine test dose for the management of labouring patients. Adding hydromorphone $300 \mu \mathrm{g}$ does not prolong the analgesic duration. When performing an ambulatory epidural in early labour, after a lidocaine and epinephrine test dose, we found no advantage in adding hydromorphone $300 \mu \mathrm{g}$ to fentanyl.

\section{Acknowledgement}

The authors appreciate the secretarial assistance of Ms. Lynda Paglia.

\section{References}

1 Dunn SM, Connelly NR, Steinberg RB, et al. Intrathecal sufentanil versus epidural lidocaine with epinephrine and sufentanil for early labor analgesia. Anesth Analg 1998; 87: 331-5.

2 Connelly NR, Mainkar T, El-Mansouri M, et al. Effect of epidural clonidine added to epidural sufentanil for labor pain management. International Journal of Obstetric Anesthesia 2000; 9: 94-8.

3 Connelly NR, Parker RK, Vallurupalli V, Bhopatkar S, Dunn $S$. Comparison of epidural fentanyl versus epidural sufentanil for analgesia in ambulatory patients in early labor. Anesth Analg 2000; 91: 374-8.

4 Connelly NR, Parker RK, Lucas T, et al. The influence of a bupivacaine and fentanyl epidural infusion after epidural fentanyl in patients allowed to ambulate in early labor. Anesth Analg 2001; 93: 1001-5.

5 Steinberg RB, Dunn SM, Dixon DE, Rehm KL, Pastides $H, H u X$. Comparison of sufentanil, bupivacaine, and their combination for epidural analgesia in obstetrics. Reg Anesth 1992; 17: 131-8.

6 Steinberg RB, Powell G, Hu X, Dunn SM. Epidural sufentanil for analgesia for labor and delivery. Reg Anesth 1989; 14: 225-8.

7 Bromage PR. Epidural Anesthesia. Philadelphia: WB
Saunders, 1978: 144.

8 Parker RK, White PF. Epidural patient-controlled analgesia: an alternative to intravenous patient- controlled analgesia for pain relief after cesarean delivery. Anesth Analg 1992; 75: 245-51.

9 Parker RK, Sawaki $\Upsilon$, White PF. Epidural patient-controlled analgesia: influence of bupivacaine and hydromorphone basal infusion on pain control after cesarean delivery. Anesth Analg 1992; 75: 740-6.

10 Halpern SH, Arellano R, Preston R, et al. Epidural morphine vs hydromorphone in post-Caesarean section patients. Can J Anaesth 1996; 43: 595-8.

11 Norris MC, Grieco WM, Borkowski M, et al. Complications of labor analgesia: epidural versus combined spinal epidural techniques. Anesth Analg 1994; 79: 529-37.

12 Gleeson CM, Reynolds F. Accidental dural puncture rates in UK practice. International Journal of Obstetric Anesthesia 1998; 7: 242-6.

13 Buggy DJ, MacDowell C. Extradural analgesia with clonidine and fentanyl compared with $0.25 \%$ bupivacaine in the first stage of labour. Br J Anaesth 1996; 76: 319-21.

14 Breen TW, Giesinger CM, Halpern SH. Comparison of epidural lidocaine and fentanyl to intrathecal sufentanil for analgesia in early labour. International Journal of Obstetric Anesthesia 1999; 8: 226-30.

15 Campbell DC, Zwack RM, Crone LAL, Yip RW. Ambulatory labor epidural analgesia: bupivacaine versus ropivacaine. Anesth Analg 2000; 90: 1384-9.

16 Cohen SE, Yeh JY, Riley ET, Vogel TM. Walking with labor epidural analgesia. The impact of bupivacaine concentration and a lidocaine-epinephrine test dose. Anesthesiology 2000; 92: 387-92.

17 Fischer C, Blanié P, Jaouën E, Vayssière C, Kaloul I, Coltat JC. Ropivacaine, $0.1 \%$, plus sufentanil, 0.5 $\mu \mathrm{g} / \mathrm{ml}$, versus bupivacaine, $0.1 \%$, plus sufentanil, 0.5 $\mu \mathrm{g} / \mathrm{ml}$, using patient-controlled epidural analgesia for labor. Anesthesiology 2000; 92: 1588-93. 